\title{
REFLEXIONES ACERCA DE LA SUSPESIÓN, POR EL PRESIDENTE DE LA ASAMBLEA DE MADRID, DE LA SESIÓN PLENARIA DEL 1 DE FEBRERO DE 2001
}

\author{
ANTONIA NAVAS CASTILLO \\ Doctora en Derecho \\ Profesora del Departamento Constitucional de la UNED \\ FLORENTINA NAVAS CASTILLO \\ Doctora en Derecho \\ Profesora de.Derecho Constitucional \\ de la Universidad Rey Juan Carlos
}




\section{SUMARIO}

1. IntRoducción. 2. Reflexiones a propósito del derecho parlamentario Y la autonomía parlamentaria. 3. Reflexiones a propósito del acto parlamentario adoptado por el Presidente de la Asamblea de Madrid: A) ¿Puede el Presidente de la Asamblea de Madrid suspender la sesión plenaria del día 1 de febrero de 2001?; B) ¿Cuándo podría considerarse vulnerado el derecho de participación contenido en el artículo 23.2 de la Constitución?; C) ¿Nos encontramos ante auténticos acta interna corporis?; D) ¿Sería posible controlar jurisdiccionalmente este acto parlamentario, en el supuesto de que se hiciese efectiva la traslación de la "teoría de los actos de gobierno" a los "actos parlamentarios»? 4. A MODO DE REFLEXIÓN FINAL. 


\section{REFLEXIONES ACERCA DE LA SUSPENSIÓN, POR EL PRESIDENTE} DE LA ASAMBLEA DE MADRID, DE LA SESIÓN PLENARIA DEL 1 DE FEBRERO DE 2001

ANTONIA NAVAS CASTILLO

Doctora en Derecho

Profesora del Departamento

de Derecho Constitucional de la UNED

FLORENTINA NAVAS CASTILLO

Doctora en Derecho

Profesora de Derecho Constitucional

de la Universidad Rey Juan Carlos

\section{INTRODUCCIÓN}

La suspensión de la sesión plenaria del día 1 de febrero de 2001 de la Asamblea de Madrid, por parte de su Presidente, ante las interrupciones provocadas por el público presente en la Tribuna de invitados, ha sido objeto de duras críticas, en ciertos sectores doctrinales $y$ políticos.

Así, por ejemplo, el Portavoz Socialista, Pedro Sabando, «insistió en que se trataba de "un problema jurídico y político grave" y no de una 
"frivolidad"», añadiendo, a su vez, que la suspensión del Pleno suponía, ni más ni menos, que la vulneración "de los principios democráticos". Por su parte, en este mismo sentido, «el Catedrático de Derecho Constitucional de la Universidad de Alcalá José Juan González Encinar, a quien el PSOE había solicitado un dictamen, opinó que el caso "es un uso abusivo de la lógica de las mayorías. Un caso claro de trato arbitrario y discriminatorio, $y$, por tanto, lesivo del derecho fundamental del ejercicio de los cargos públicos en condiciones de igualdad". A su juicio, con esta decisión, utambién se lesionan los derechos fundamentales de todos los ciudadanos, que votaron en su día a los diputados"' ${ }^{\text {. }}$

Lo cierto, es que nos encontramos ante una cuestión actual de Derecho Parlamentario, que, singularmente, ha querido ser puesta en conocimiento y a juicio de la opinión pública, calificándola, erróneamente a nuestro juicio, por desproporción con los hechos acontecidos, como de "crisis institucional»", ocupando las primeras páginas de algunos diarios de ámbito nacional; motivo éste, que estimamos suficiente para despertar nuestro interés acerca de la legalidad y oportunidad de la decisión adoptada por el Presidente de la Asamblea de la Comunidad Autónoma de Madrid, y que nos obliga, por ello, a reflexionar sobre cuestiones tales, como pudieran ser, entre otras, las siguientes: ¿En qué sentido ha de entenderse hoy el principio de autonomía de las Cámaras?; ¿ante qué tipo de acto parlamentario nos encontramos?; ¿estamos ante un acta interna corporis exento de control?; ¿la decisión adoptada por el Presidente de la Asamblea es conforme a la legalidad?, ¿y conforme a la oportunidad?

\section{REFLEXIONES A PROPÓSITO DEL DERECHO PARLAMENTARIO Y LA AUTONOMÍA PARLAMENTARIA}

No encontramos obstáculo alguno que impida mantener la existencia de un sector jurídico propio del Poder Legislativo que, por girar en torno al Parlamento, se ha venido a denominar como Derecho Parlamentario ${ }^{3}$; si bien, su propia subsistencia dependerá de su inserción

1 Diario "El País", de 9 de febrero de 2001, pág. 3.

2 Diario «El País», de 9 de febrero de 2001, primera página.

3 En relación con el Derecho Parlamentario y la autonomía parlamentaria, vid. NAVAS CASTILLO, A.: El control jurisdiccional de los actos parlamentarios sin valor de ley, Colex, Madrid, 2000. También vid. Navas Castillo, F.: Las Comisiones Parlamentarias en el ordenamiento jurídico español, Servicio de Publicaciones de la Facultad de Derecho de la Universidad Complutense, Madrid, 2000. 
o no en un auténtico sistema constitucional, ya que sólo en éste el Derecho Parlamentario tiene cabida, de tal forma que, "no hay Parlamento, $y$, por consiguiente, no hay verdadero Derecho Parlamentario, allí donde no se enfrentan distintas $-y$ libremente organizadas- fuerzas políticas (...). Por consiguiente, sólo hay Derecho Parlamentario allí donde puede hablarse con rigor de Derecho Constitucional ${ }^{4}$.

Partiendo, por tanto, de tales planteamientos, el Derecho Parlamentario se configura hoy, como una disciplina jurídica integrada dentro del Derecho Constitucional, es decir, como un sector del ordenamiento jurídico y, por tanto, como auténtico Derecho objetivo en tanto sús disposiciones se presentan como obligatorias para sus destinatarios, y cuya peculiaridad reside, esencialmente, en su propio objeto, el Parlamento, por ser precisamente ésta la institución democrática por excelencia en tanto representante de la voluntad popular libre y democráticamente manifestada.

Ahora bien, en el estudio del Derecho Parlamentario, concebido éste como el "conjunto de normas y de relaciones constituidas a su amparo que regulan la organización y funcionamiento de las Cámaras Parlamentarias, entendidas como órganos que asumen la representación popular en un Estado Constitucional y Democrático de Derecho y el ejercicio de sus funciones supremas" ${ }^{5}$, deberán tenerse en cuenta las siguientes circunstancias:

- Primero: El proceso de transición del Estado Liberal al Estado Social de nuestros días, lo que provoca la necesidad de que se lleve a cabo todo un proceso de revisión conceptual.

- Segundo: La determinación del contenido del Derecho Parlamentario; debiendo, en todo caso, dicho contenido, adecuarse a los principios inspiradores de un Estado Democrático como es el nuestro.

- Tercero: Las propias singularidades del Derecho Parlamentario consecuencia de su evolución histórica. Singularidades, éstas, que deberán ser enfocadas a la luz de los grandes principios inspiradores de su posición constitucional, teniendo en cuenta el proceso de transformación al que estamos asistiendo. Nos estamos refiriendo:

4 Santaolalla López, F.: Derecho Parlamentario español, Espasa Calpe, 1990, Madrid, pág. 28. También vid. Alzaga VILLAAMLL, O.: "Contribución al estudio del Derecho Parlamentario", Revista de Derecho Público, n. 62, 1976, págs. 19 y ss.

5 Santaolalla López, F.: Derecho Parlamentario español, op. cit., pág. 30. 
a) Al Principio de autonomía de las Cámaras, configurado por la concepción liberal del Derecho Parlamentario, como aquella técnica tendente a garantizar la libertad del Parlamento, de sus órganos y de sus miembros, frente a las posibles injerencias de los demás poderes públicos. Configuración ésta, que precisa de toda una revisión conceptual, que tendrá su fundamentación en el principio democrático.

b) Consecuencia directa de lo expuesto anteriormente, sería el principio de autonormación, que afecta a cuestiones tales como la propia configuración de nuestro sistema de fuentes, los derechos y libertades de los ciudadanos, las relaciones interorgánicas entre los diversos poderes públicos... etc.

c) El principio de vinculación de todos los poderes públicos a la Constitución y al resto del ordenamiento jurídico, que, como ciertamente señala TORRES DEL MORAL ${ }^{6}$, supone el reconocimiento implícito del principio de supremacía de la Constitución, equivaliendo, por tanto, a una declaración del Estado de Derecho.

d) El principio democrático, que se convierte en el criterio fundamentador de toda la dogmática constitucional, frente a los postulados que en su momento representó el principio monárquico.

En efecto, el Derecho Parlamentario es una rama jurídica dotada de caracteres específicos y principios propios, que se circunscribe en un ámbito normativo más amplio, cual es el Derecho Constitucional, al ser la Constitución en la que encuentra su fundamento y su límite ${ }^{7}$. De tal forma, que el Derecho Parlamentario actual, como consecuencia de la transformación del Estado Liberal al Estado Social y Democrático de nuestros días, no encuentra ya su fundamento en el principio de autonomía parlamentaria en su concepción de "privilegio", como era pro-

6 Torres del Moral, A.: Principios de Derecho Constitucional Español, Vol.Il. Facultad de Derecho de la Universidad Complutense, Madrid, 1992, pág. 62.

7 Mantienen la autonomía del derecho Parlamentario respecto del Derecho Constitucional, entre otros, Di Clolo, V.: Le fonti del Diritto Parlamentare, 2. ed; Giuffrè Editore, Milano, 1975, pág. 9. También en /I Diritto Parlamentare nella teoria e nella pratica, Giuffrè Editore, Milano, 1980, págs. 3 y ss.; LONGI, V.: Elementi di Diritto e procedura parlamentare, Giuffrè, Milano, 1978, págs. 3 y ss. También en Ed. de 1991. 
pio del Derecho Parlamentario decimonónico, sino en la autonomía reconocida a nivel constitucional en su concepción de instrumento que garantiza la "independencia" y la potestad de autonormación del Parlamento, concepción ésta más acorde con los principios que inspiran nuestro Estado democrático.

En este orden de ideas, esta "independencia", o, como la denomina PUNSET BLANCO ${ }^{8}$, autonomía orgánica-funcional del Parlamento, no se puede traducir hoy en discrecionalidad sin límites, pues ello, supondría la vulneración del principio democrático. Es decir, autonomía no equivale a soberanía ni a arbitrariedad, y, por tanto, la autonomía parlamentaria no se transforma ya en autonomía jurisdiccional.

$Y$ es que, difícilmente se puede admitir la exclusión general de cualquier tipo de control jurisdiccional de los actos parlamentarios en un marco jurídico presidido por una Constitución, como la española, en la que: de un lado, se preceptúa el sometimiento de todos los poderes públicos a la Constitución y al resto del ordenamiento (art. 9.1 CE), garantizándose el principio de legalidad y la interdicción de la arbitrariedad de los poderes públicos, lo que necesariamente requiere que se articulen los mecanismos que sirvan para controlar el cumplimiento efectivo de dicho sometimiento; $y$ de otro, se consagra un amplio catálogo de derechos y libertades, lo que igualmente se traduce en el reconocimiento de las garantías que hagan efectiva su protección, derechos y libertades, que por vincular a todos los poderes públicos, deberán también hacerse efectivos frente a las vulneraciones que de ellos se puedan producir como consecuencia de la actividad parlamentaria.

En consecuencia, el Derecho Parlamentario no se configura ya tan sólo como una "técnica de libertad del Parlamento", sino también como una "técnica de libertad en el Parlamento y frente al Parlamento" ${ }^{9}$, es decir, un Derecho Parlamentario entendido, no como ordenamiento parlamentario autónomo, dado que no es posible hablar de soberanía parlamentaria, sino como disciplina jurídica que se integra en otra más amplia, el Derecho Constitucional, que a su vez, forma par-

8 Punset Blanco, R.: Las Cortes Generales, Centro de Estudios Constitucionales, Madrid, 1983, págs. 89 y ss. También vid. "Los Reglamentos de las Cortes Generales", Revista de Derecho Político, n.. 82, 1982, pág. 333.

9 Fernández-Miranda Campoamor, A.: "Prólogo" al libro de Torres Muro, I.: Los órganos de gobierno de las Cámaras, Congreso de los Diputados, Madrid, 1990, pág. 10. Álvarez Conde, E.: Curso de Derecho Constitucional.Vol.ll, Tecnos, Madrid, 2000, pág. 110. 
te del ordenamiento jurídico del Estado al que la Constitución, en virtud de su superioridad normativa, dota de unidad.

Un Derecho, que en palabras de Aragón Reyes:

a) no está integrado exclusivamente por normas que afectan al Parlamento;

b) tampoco cabe entender que dicho Derecho lo componen exclusivamente normas que regulan la organización de las funciones supremas de la Cámara;

c) el Derecho Parlamentario no resulta separable del Derecho del Estado; Y

d) los interna corporis acta han de ser susceptibles de control de constitucionalidad $^{10}$.

Desde tales consideraciones, LópEZ-GARRIDO ${ }^{11}$ distingue, de un lado, lo que ha venido a denominar como "núcleo esencial» del Derecho Parlamentario, en el que se integran todo ese conjunto de relaciones jurídicas en las que el Parlamento o sus órganos son al mismo tiempo actor y sujeto pasivo, esto es, aquellas relaciones jurídicas en las que existe una identidad entre el sujeto y el objeto del Derecho, por ser las mismas Cámaras o sus órganos, tanto los que crean el Derecho como los destinatarios de ese Derecho; de otro, aquel conjunto de relaciones juridicas en donde no existe coincidencia entre el sujeto y el objeto del Derecho, que tienen lugar cuando el Parlamento se relaciona bien con personas privadas, bien con su propio funcionariado, bien con otros órganos constitucionales, bloque normativo éste que se ha venido a denominar como "Derecho Parlamentario administrativo" ${ }^{12}$. En realidad se trata de dos ámbitos diferenciados, respecto de los cuales se han venido manteniendo diferentes posturas, tanto doctrinales como jurisprudenciales, acerca de la posibilidad de su enjuiciamiento jurisdiccional.

10 Aragón Reyes, M.: "Las fuentes del Derecho Parlamentario", Ponencia presentada en el Seminario organizado por el Parlamento Vasco sobre "Las Fuentes del Derecho Parlamentarion, Vitoria, 25 y 26 de octubre de 1995.

11 López-GARRIDO, D.: "La producción del Derecho Parlamentario. Una nueva perspectiva sobre su naturaleza", en I Jornadas de Derecho Parlamentario, Vol.l, Congreso de los Diputados, 1985, pág. 178.

12 Ripollés Serrano, R.: "La autonomía administrativa de las Cortes Generales", en I Jornadas de Derecho Parlamentario, Vol. II, Congreso de los Diputados, 1985, págs. 663 y ss. Frente a la denominación "Derecho Administrativo Parlamentario" acuñada por GARRIDO FALLA, F, "La Administración Parlamentaria", en I. Jornadas de Derecho Parlamentario, Vol.I, Congreso de los Diputados, 1985, págs. 91 y ss. 
En cualquier caso, creemos que las referencias manifestadas hasta este momento pueden ser suficientes para afirmar la existencia de un ámbito normativo propio del Parlamento.

\section{REFLEXIONES A PROPÓSITO DEL ACTO PARLAMENTARIO ADOPTADO POR EL PRESIDENTE DE LA ASAMBLEA DE MADRID}

El acto de suspensión de la sesión plenaria del día 1 de febrero por parte del Presidente de la Asamblea de Madrid, es un acto parlamentario sin valor de ley de naturaleza no administrativa ${ }^{13}$, que afecta al ámbito interno de la Cámara. Esto es, en principio se trata de un acto interno de un órgano parlamentario (el Presidente) que, de conformidad con la jurisprudencia del Tribunal Constitucional, únicamente podrá ser objeto de fiscalización cuando suponga la vulneración de un derecho fundamental, pues sólo en tal caso, el acto parlamentario sale o transciende "la esfera irrevisable propia de los interna corporis acta" convirtiéndose en un acto fiscalizable ante el Tribunal Constitucional, al que corresponde el examen de la virtual lesión de tal derecho o libertad (ATC 12/1986, de 15 de enero).

Asi es, el Tribunal Constitucional ha venido reconociendo la existencia de los denominados acta interna corporis y su exención del control jurisdiccional (ATC 12/1986), pero, así mismo, admite su control jurisdiccional siempre que dichos actos afecten a las relaciones externas del órgano o supongan la violación de derechos fundamentales (ATC 183/1984; SSTC 118/1988, 161/1988 etc) ${ }^{14}$.

Siguiendo con esta línea argumental, nos parece necesario reflexionar sobre las siguientes cuestiones:

A) ¿Puede el Presidente de la Asamblea de Madrid suspender la sesión plenaria del día 1 de febrero de 2001?

B) ¿Cuando podría considerarse vulnerado el derecho de participación contenido en el artículo 23.2 de la Constitución?

C) ¿Nos encontramos ante auténticos acta interna corporis?

13 Sobre el concepto y las clases de actos parlamentarios vid. NAVAS CASTILLO, A.: El control jurisdiccional de los actos parlamentarios sin valor de ley, op. cit., págs. 25 a 63 .

14 Sobre la revisión conceptual de la teoría de los acta interna corporis vid. Navas Castlllo, A.: El control jurisdiccional de los actos parlamentarios sin valor de ley, op. cit. págs. 63 a 151. 
D) ¿Sería posible controlar jurisdiccionalmente este acto parlamentario, en el supuesto de que se hiciese efectiva la traslación de la "teoría de los actos de gobierno" a los "actos parlamentarios"?

\section{A) ¿Puede el Presidente de la Asamblea suspender la sesión plenaria del día 1 de febrero de 2001?}

En el caso que nos ocupa, la decisión parlamentaria del Presidente supondría la vulneración de los derechos de las minorías, y en concreto la conculcación del derecho contenido en el art. 23.2 de la CE, sólo cuando dicho acto parlamentario no se haya conformado de acuerdo con el procedimiento previsto por el Reglamento de la Asamblea, o bien, cuando no haya sido adoptado por el órgano legitimado para producirlo (en este caso el Presidente), pues, de ser así, esa cierta discrecionalidad del acto parlamentario de decisión por parte del Presidente, se traduciría en mera arbitrariedad y, por tanto, la decisión parlamentaria del Presidente trascendería su ámbito interno para pasar a convertirse en un acto parlamentario sin valor de ley fiscalizable en tanto vulnerador del derecho contenido en el art. 23 de la Constitución.

Para poder determinar si el acto parlamentario del Presidente trasciende, en este caso, su ámbito interno $y$, en consecuencia, se convierte en un acto fiscalizable, habrá que establecer si el Presidente ha actuado de acuerdo con lo previsto en el Reglamento de la Asamblea $y$, además, si es el órgano competente para adoptar la decisión de suspensión de la sesión plenaria.

Para ello se requiere un análisis sistemático de los arts. 109 y 137.2 del Reglamento de la Asamblea de Madrid, en cuya virtud:

- art. 109: "las sesiones del Pleno y de las Comisiones no serán levantadas hasta que no se hayan tramitado todos los asuntos incluidos en el orden del día, sin perjuicio de las posibles alteraciones del mismo reguladas en este Reglamento"

- art. 137.2: "El Presidente velará por el mantenimiento de la disciplina, el orden y la cortesía parlamentaria en el recinto de la Asamblea y en todas sus dependencias, a cuyo efecto podrá adoptar las medidas al respecto en este Reglamento y, asimismo, cualquier otra que considere oportuna, pudiendo incluso poner a disposición judicial a las personas responsables". 
Asi es, a pesar de que el art. 109 establece que las sesiones del Pleno no serán levantadas hasta que no se hayan tramitado todos los asuntos incluidos en el orden del día, el art. 137, por su parte, otorga al Presidente de la Cámara la facultad de velar por el mantenimiento de la disciplina, el orden y la cortesía parlamentaria en el recinto de la Asamblea y en todas sus dependencias, a cuyo efecto podrá adoptar las medidas previstas al respecto en el Reglamento y, asimismo, cualquier otra que considere oportuna.

Se observa, pues, que el Presidente, en virtud de la competencia que le atribuye el art. 137.2 del Reglamento, optó por suspender la sesión plenaria, dado el escándalo que se había producido en la Cámara. Se trata, entonces, de una decisión parlamentaria adoptada por el órgano legitimado para ello y de acuerdo con lo previsto por el Reglamento de la Asamblea, de manera que el acto de decisión del Presidente bien puede merecer la calificación de "acta interna corporis", esto es, de un acto parlamentario sin valor de ley exento de control jurisdiccional, en tanto no supone la vulneración de los derechos de las minorías $y$, consecuentemente, no transciende su ámbito interno.

\section{B) ¿Cuándo podría considerarse vulnerado el derecho de participación contenido en el art. 23.2 de la Constitución?}

De conformidad con la jurisprudencia de nuestro Tribunal Constitucional, el derecho del art. 23.2 de la CE es un derecho de configuración legal, es por ello que "compete a la ley, comprensiva según se deja dicho, de los Reglamentos Parlamentarios, el ordenar los derechos y facultades que corresponden a los distintos cargos y funciones públicas. Una vez creadas por las normas legales tales derechos y facultades éstos quedan integrados en el status propio de cada cargo con la consecuencia de que podrán sus titulares, al amparo del art. 23.2 de la $C E$, defender ante los órganos judiciales $-y$ en último extremo ante este Tribunal- el ius in officium que consideren ilegítimamente constreñido o ignorado por actos del poder público, incluidos los provenientes del propio órgano en el que se integren los titulares del cargo, con la especialidad de que si el órgano es parlamentario la defensa del derecho deberá promoverse directamente ante esta jurisdicción constitucional en aplicación de lo dispuesto en el art. 42 de la LOTC" (STC 161/1988). Doctrina, por otra parte que el Tribunal Constitucional reitera en jurisprudencia posterior (ATC 52/1994). 
Así es, de acuerdo con la jurisprudencia mantenida por el Tribunal Constitucional, se produce una vulneración del derecho contenido en el art. 23.2 CE, siempre que un acto sin valor de ley de un órgano parlamentario (en este caso el Presidente) vulnere un derecho o una facultad que el Reglamento de la Cámara atribuya al parlamentario en el ejercicio de sus funciones públicas, ya que, son los Reglamentos parlamentarios los que determinan el significado propio del derecho previsto en el art. 23.2 CE, es decir, son los que definen el ius in officium de los parlamentarios, al haber incorporado, el Tribunal Constitucional a través de su reiterada jurisprudencia, las facultades que integran el estatuto parlamentario al derecho de participación que consagra el art. 23.2 de la Constitución, lo que, por otra parte, conlleva a la consideración del Reglamento Parlamentario como parámetro de constitucionalidad.

Desde estas premisas, en el caso que nos ocupa, podría considerarse vulnerado el derecho de participación política contenido en el art. 23.2 de la $C E$, siempre que el acto de fijación del orden del día no se hubiere conformado de acuerdo con el procedimiento y por el órgano legitimado para producirlo en atención a lo previsto por el Reglamento de la Cámara, pues de ser asi, no quedaría garantizado el respeto a los derechos de las minorías parlamentarias.

Pues bien, para determinar si, efectivamente, se ha producido o no la vulneración del derecho previsto en el art. 23.2 de la CE, será conveniente distinguir 3 cuestiones distintas:

a) El día 6 de febrero el Presidente, de acuerdo con la Junta de Portavoces, decide que los puntos del orden del día no tratados en la sesión plenaria del día 1 de la Asamblea, se incluirán en el orden del día de las sesiones plenarias que tendrán lugar los días 8 y 15 de febrero.

* A tenor del art. 106 del Reglamento, el orden del día deberá ser fijado por el Presidente de acuerdo con la Junta de Portavoces (también art. 61.1.g del Reglamento).

* Por otra parte, los acuerdos de la Junta de Portavoces se adoptarán siempre en función del criterio de voto ponderado (art. 60 del Reglamento).

* El Reglamento de la Asamblea no establece cuando se entiende que la Junta de Portavoces se encuentra reglamentariamente constituida.

Tenidas en cuenta las observaciones anteriores, aunque el Partido Socialista se retire de la Junta de Portavoces, siem- 
pre que se considere que la Junta de Portavoces se encuentra reglamentariamente constituida, parece que el acto de determinación del orden del día ha sido adoptado de conformidad con el procedimiento establecido en el Reglamento y por el órgano (Presidente y Junta de Portavoces) legitimado para ello.

Desde esta perspectiva, la decisión parlamentaria adoptada, en tal caso, por el Presidente de acuerdo con la Junta de Portavoces, no supondría, tampoco aquí, la vulneración del derecho de participación consagrado en el art. 23.2 de la Constitución.

b) El Presidente de la Asamblea convoca la sesión plenaria del día 8 de febrero.

- Los grupos parlamentarios del Partido Socialista e Izquierda Unida no acuden a la sesión plenaria.

- El Presidente indica que se acuerda tramitar las iniciativas pendientes de la sesión plenaria del día 1 de febrero en sesiones posteriores.

En este supuesto, nos encontramos ante una modificación del orden del día, al no haberse discutido en esta sesión los puntos pendientes de la sesión del día 1 de febrero, tal y como se acordó el día 6.

En virtud del art. 106.3 del Reglamento de la Asamblea, el orden del día del Pleno podrá ser alterado por acuerdo de ésta a propuesta del Presidente o a petición de 1 grupo parlamentario o $1 / 5$ de sus miembros.

En tal caso, si el Pleno se encuentra reglamentariamente constituido, aún no habiendo asistido a la sesión plenaria los grupos parlamentarios del Partido Socialista e Izquierda Unida, la modificación del orden del día producida en la sesión plenaria del día 8 de febrero se habría efectuado conforme a lo previsto en el Reglamento.

El acto parlamentario de modificación del orden del día tampoco supondría, entonces, la vulneración del derecho contenido en el art. 23.2 de la CE.

c) ¿Los parlamentarios (PSOE, IU) tienen la facultad reconocida por el Reglamento de poder exigir que los puntos pendientes del orden del día de la sesión plenaria del dia 1 de febrero sean discutidos en la sesión plenaria inmediatamente siguiente, sin que. quepa, en ningún caso, decisión parlamentaria en contrario? 
Dada la fuerza expansiva que el Tribunal Constitucional en reiterada jurisprudencia (STC 118/1995, de 17 de julio) ha otorgado al derecho contenido en el art. 23.2 de la $C E$, al haber incorporado las facultades que integran el estatuto parlamentario al derecho de participación que se consagra en tal precepto, sólo si los parlamentarios tienen reconocida, por parte del Reglamento de la Asamblea, la facultad de exigir que los puntos pendientes del orden del día de la sesión plenaria del día 1 de febrero sean discutidos en la sesión plenaria inmediatamente siguiente, se podrá entender que la decisión parlamentaria de modificación del orden del día de la sesión plenaria del día 8 de febrero supondrá la vulneración del derecho de participación de las minorías parlamentarias consagrado en el art. 23.2 de la CE.

$Y$ es que, como ya se ha dejado dicho, un acto parlamentario sin valor de ley, vulnera el derecho contenido en el art. 23.2 de la CE siempre que conculque una facultad o un derecho que el Reglamento de la Cámara atribuya a los parlamentarios o a sus grupos, en el ejercicio de sus funciones públicas, en tanto el Tribunal Constitucional integra el estatuto parlamentario al derecho de participación consagrado en el art. 23.2 de la $C E$, pues, en tal caso, el acto parlamentario en cuestión no habría agotado sus efectos en el ámbito de lo puramente doméstico que es característico de los interna corporis.

Pues bien, el Reglamento de la Asamblea de Madrid no establece nada al respecto, es decir, no otorga a los parlamentarios ni a sus grupos la facultad en que consiste tal exigencia.

Es por ello que, el derecho de participación contenido en el art. 23.2 de la CE, no debe considerarse vulnerado por la decisión parlamentaria de modificación del orden del dia de la sesión plenaria del día 8 de febrero, dado que la alteración antedicha se ha producido de acuerdo con lo previsto por el propio Reglamento de la Asamblea.

Pero además, se ha de advertir que el derecho contenido en el art. 23.2 no puede entenderse vulnerado porque, en este caso, la decisión parlamentaria no niega que los puntos pendientes de tratamiento en la sesión plenaria del día 1 vayan a ser tramitados, sino que, simplemente, se limita a acordar que dichos puntos se tramiten en sesiones plenarias posteriores. 
Así es, el derecho de participación que consagra nuestra Constitución y que ampara la función pública de los parlamentarios, se vería vulnerado siempre que se adoptase la decisión de no tramitar los puntos que quedaron pendientes en la sesión plenaria del día 1 de febrero, pero no en otro caso, y mucho menos si la modificación del orden del día decidida en la sesión plenaria del dia 8 ha tenido su causa en la no comparecencia de los parlamentarios que pertenecen a los grupos parlamentarios del Partido Socialista e Izquierda Unida, pues más bien, en esta ocasión, lo que en realidad se produce es el incumplimiento de un deber por parte de las minorías parlamentarias en cuestión, esto es, el deber de los Diputados de asistir a las sesiones del Pleno y a la de las Comisiones de las que formen parte (art. 25 del Reglamento de la Asamblea).

\section{C) ¿Nos encontramos ante auténticos acta interna corporis?}

Desde las premisas expuestas, los actos parlamentarios decididos, bien por el Presidente (suspensión de la sesión plenaria del día 1 de febrero), bien por el Presidente de acuerdo con la Junta de Portavoces (fijación el 6 de febrero del orden del día para los días 8 y 15 de febrero, a fin de tramitar los puntos pendientes de la sesión del día 1 de febrero, y modificación del orden del día en la sesión del 8 de febrero ante la incomparecencia de los grupos parlamentarios del Partido Socialista e Izquierda Unida, así como la decisión de tramitar los puntos pendientes de la sesión plenaria del día 1 de febrero en sesiones posteriores), son, en cualquier caso, decisiones parlamentarias que carecen del valor de la ley y de carácter interno.

Así es, pues, dado que no suponen la lesión de ningún derecho fundamental, al haber sido efectuadas por el órgano competente y de conformidad con el procedimiento establecido en el Reglamento de la Cámara, sin que, además, supongan la lesión de ninguna de las facultades que la misma norma atribuye a los parlamentarios en el ejercicio de su función pública, estas decisiones parlamentarias sin valor de ley agotan sus efectos en el ámbito de lo puramente doméstico, es decir, no transcienden la esfera irrevisable propia de los interna corporis.

En consecuencia, nos encontramos ante decisiones parlamentarias que bien merecen la calificación de verdaderos acta interna corporis, esto es, ante actos internos de la Cámara exentos de control jurisdiccional, cuya existencia viene a reconocer el Tribunal Constitucional. 


\section{D) ¿Sería posible controlar jurisdiccionalmente este acto parlamentario, en el supuesto de que se hiciese efectiva la traslación de la "teoría de los actos de gobierno" a los uactos parlamentarios" ? $^{15}$}

Quizás, para aquellos actos parlamentarios sin valor de ley de naturaleza no administrativa, que no supongan la vulneración de ninguno de los derechos fundamentales constitucionalmente amparables ante el Tribunal Constitucional, y en los que se adoptaran decisiones de naturaleza política, fuera posible trasladar la teoría de los uactos de gobierno" a los "actos parlamentarios", en el sentido, de poder controlar jurisdiccionalmente, esta vez en vía ordinaria, los elementos reglados del acto, esto es, los elementos definidos legalmente -procedimiento y competencia-, a los efectos de que la discrecionalidad no devenga, en ningún caso, en arbitrariedad, dándose, con ello, cumplimiento al mandato constitucional consagrado en el artículo 9.1 de la Constitución, en cuya virtud, todos los poderes públicos, y, por tanto, también el Parlamento, se encuentran sometidos a la Constitución y a las leyes.

En tal caso, nos encontramos ante un control de legalidad, que no de oportunidad política; pues, no se trata de llevar a cabo un control de la decisión política propiamente dicha, sino al contrario, del cumplimiento de las exigencias legalmente establecidas.

Lo cierto, es que en el supuesto que nos ocupa, ninguna de las decisiones parlamentarias que se suceden, suponen la vulneración de los requisitos y exigencias que, en cuanto al procedimiento y competencia, se prevén por la norma (Reglamento Parlamentario de la Asamblea Legislativa de la Comunidad Autónoma de Madrid), en tanto han sido adoptadas por el órgano/s, en su caso, legitimados para ello y de conformidad con el procedimiento legalmente previsto.

\section{A MODO DE REFLEXIÓN FINAL}

A nuestro juicio, y por todas las razones expuestas a lo largo de éstas páginas, el Presidente de la Asamblea Legislativa de la Comunidad Autónoma de Madrid actuó conforme a Derecho, al suspender la

15 Sobre la traslación de la "teoría de los actos políticos o actos de gobierno" a los "actos parlamentarios". vid. NAVAS CASTILLO, A.: El control jurisdiccional de los actos parlamentarios sin valor de ley, op. cit. pp 124-130. 
sesión plenaria del día 1 de febrero de 2001, ante las interrupciones provocadas por el público presente en la tribuna de invitados. Y ello, especialmente, porque, como ya se ha puesto de relieve, la "suspensión de la sesión", además de efectuarse por el órgano competente y de conformidad con el procedimiento establecido en el Reglamento de la Cámara, no implica, en ningún caso, el "levantamiento» de la misma.

Sin embargo, si bien es cierto que el Presidente de la Asamblea de la Comunidad Autónoma de Madrid actuó de conformidad con la legalidad; también lo es, que dicha actuación, ha provocado la suficiente insatisfacción entre los representantes del pueblo madrileño en la Cámara, como para que, la misma, haya sido puesta sobre el tapete ante la opinión pública, hasta el punto de ser noticia de primera página en algunos diarios de ámbito nacional.

Esta circunstancia, entendemos, que deberia hacer, al menos; reflexionar a quienes ostentan el cargo de cualquier órgano de dirección en las Cámaras, y muy especialmente, a quienes ostentan la condición de Presidente de ésta; pues, no debemos olvidar que el Presidente de toda Asamblea representativa debe ejercer sus funciones con neutralidad $y$ perspectiva institucional ${ }^{16}$. $Y$ es que, aun cuando "se manifiesta cierta tendencia hacia la consideración del Presidente de la Cámara como hombre de la mayoría parlamentaria y, por tanto, del Gobierno emanado de dicha mayoría" "17, sería más que deseable, que, como ha señalado MoHroff, estuviésemos ante una institución "con dos almas: una que comparte las orientaciones de la mayoría gubernativa y otra que tutela la independencia constitucional del órgano que preside y los derechos imprescriptibles de las minorías $)^{18}$. De tal manera, que sea imprescindible plantearse la siguiente cuestión: ¿existe, en este caso, una relación de proporcionalidad entre la medida adoptada por el Presidente de la Asamblea Legislativa de la Comunidad Autónoma de Madrid, y los hechos acontecidos que devinieron en la causa de tal decisión?

Por lo demás, dado que nos encontramos, como ya expusimos anteriormente, ante decisiones parlamentarias que bien merecen la calificación de verdaderos acta interna corporis, y por entender, que

16 Torres Muro, l.: Los órganos de gobierno de las Cámaras, Congreso de los Diputados, Madrid, 1987, pág. 58.

17 García Morillo, J.: El régimen constitucional español, (dir) De Esteban, J. Y López Guerra, Barcelona, 1982, pág. 93.

18 Mohroff: Introduzione ad uno studio...istituto presidenziale del Parlamento italiano (1848-1952), Roma, 1962, pág. 35. 
dichos actos internos de las Cámaras no "pueden tener la misma significación que tenían en el constitucionalismo liberal, debiendo hoy procederse a toda una nueva categorización conceptual que ha de responder al principio general de justiciabilidad de los actos parlamentarios, siendo la existencia de los acta interna corporis, que deben interpretarse con criterio restrictivo, una excepción a dicha reglas ${ }^{19}$; proponemos la creación, a través de las normas de autoorganización interna de las Cámaras, de todo un sistema de recursos parlamentarios propio, que permita llevar a cabo, no sólo ya un control de legalidad de los actos internos de las Cámaras, sino, incluso, y por qué no, de proporcionalidad de los mismos. Con esta propuesta, quizás, sería posible evitar hechos tan desagradables como los que han acontecido, estos días, en un Parlamento autonómico, la Asamblea Legislativa de la Comunidad de Madrid. En suma, deberán arbitrarse mecanismos que impidan que suceda lo que ya ha sucedido, pues, como ciertamente dijera MaHATMA GANDHI: "La democracia se romperá con las riendas tensas. Sólo podrá existir apoyada en la confianza".

19 Álvarez Conde, E.: Curso de Derecho Constitucional, Vol. Il, Tecnos, Madrid, 2000, pág. 115. 